\title{
SOUTH AFRICA'S 2016 MUNICIPAL ELECTIONS \\ How the ANC and DA leveraged Twitter to Capture the Urban Vote
}

\section{Ronesh Dhawraj, Danie du Plessis and Charmaine du Plessis}

Ronesh Dhawraj is a specialist researcher in politics at the South African Broadcasting Corporation, KwaZulu-Natal, South Africa

Danie du Plessis is a professor, Department of Communication Science, University of South Africa, Pretoria, South Africa

Charmaine du Plessis is a professor, Department of Communication Science, University of South Africa, Pretoria, South Africa

\begin{abstract}
This paper focuses on how South Africa's governing party, the African National Congress (ANC), and main opposition, the Democratic Alliance (DA), leveraged microblogging site Twitter. This was part of their urban election campaign arsenal in the 2016 local government elections (LGE) to promote party-political digital issue ownership within an urban context. Using each party's corpus of 2016 election-related tweets and election manifestos, this three-phased grounded theory study found that each party used Twitter as a digital political communication platform to communicate their election campaigns. The DA notably leveraged the social networking site more for intense focused messaging of its negative campaign against the ANC while simultaneously promoting positive electoral messages around its own core issues and metro (urban) mayoral candidates. Furthermore, battleground metros were identified, narrow-cast and subsequently audiencesegmented by the party in Ekurhuleni, Johannesburg, Tshwane (in Gauteng) and Nelson Mandela Bay (in the Eastern Cape). This led to an emphasised campaign to either activate the party's own urban support base and/or to suppress the ANC's turnout in these highly-contested areas. The results of this study further indicate that the ANC and DA both used Twitter to claim explicit and implicit digital party-political issue ownership in the 2016 LGE.
\end{abstract}

Keywords: South Africa, electoral politics, grounded theory, digital issue ownership, political communication, social media, Twitter, urban electioneering 


\section{INTRODUCTION}

South Africa holds elections for national, provincial and local government representatives every five years. While the country's most recent general elections took place in May 2019, local councillors were last voted into office on 3 August 2016. The country's sixth local government elections are scheduled to take place on Wednesday 27 October 2021. While there may have been a wealth of local government issues that occupied the public domain preceding the August 2016 poll, the dominant narrative for the election at the time was undoubtedly the battle for the urban vote and how residents in South Africa's eight metropoles would vote.

This was an election tailor-made for the DA, South Africa's main opposition party, considering that the party draws most of its support from urban constituencies. For this reason, DA national marketing director Aimee Franklin (2018) confirms that 'battleground metros' were identified in Gauteng (Johannesburg, Tshwane and Ekurhuleni) and the Eastern Cape (Nelson Mandela Bay) as early as the pre-campaigning phase. Vote-catching strategies were put in place and electoral messages 'narrow-casted' to ensure maximum 'audiencesegmentation'. For the DA, these battleground metros were singled out due to perceived ANC leadership and governance weaknesses there (Berkowitz 2016). Surveys by organisations such as IPSOS also primed the highly-charged 2016 electoral landscape, using fresh updates on just how close the urban race was for votes in the four ANC-led metros (IPSOS 2016a).

Everatt (2017) observes that having Jacob Zuma as party president at the time did not do the ANC any favours. Despite his popularity in some provinces, Zuma was not well-liked in Gauteng's urban areas, the three metropolitan municipalities. Opting to keep the scandal-prone president out of the urban centres, the ANC decided to use other urban-friendly leaders such as Kgalema Motlanthe to convey the ANC's 2016 message. Part of the party's media blitz in the metros was aimed specifically at the millions of middle-class black voters who had benefited from ANC pro-reformist policies since 1994 (Mantashe 2017, p. 14). However, opposition parties like the DA still capitalised on the ANC's leadership deficit by consistently honing in on the ANC president to campaign negatively against the party. This focused onslaught against the incumbent was implemented to further bolster the DA's chances among a more-educated and technologically-savvy urban electorate; and for the DA, this proved an easy task given its urban-centric ideological leaning (Franklin 2018). The ANC, on the other hand, had been consistently losing electoral support among this important demographic, which now constituted approximately $41 \%$ of total voters. The party's own internal polling also illustrated 
how difficult the battle was likely to be in Johannesburg, Ekurhuleni, Tshwane and Nelson Mandela Bay (Sunday Independent 2013).

Madia (2019) notes that while the DA relies largely on town hall meetings and community gatherings to spread its electoral campaign message, the ANC's electioneering arsenal consists mainly of door-to-door visits and walkabouts conducted across South Africa's nine provinces. Accessing gated communities and middle-class residents in high-walled urban (and suburban) homes needed a different strategy because door-to-door visits would not work, as potential metro voters were accustomed to accessing news about their communities through multiple media platforms. Significantly, younger middle-class citizens were now using social media platforms to criticise the party's purported non-delivery; and this disconnect was beginning to worry the ANC (Mantashe 2017, p.14). Also, the ANC itself lamented that the urban middle-class did not attend its rallies or similar party-political events (Sunday Independent 2013). This urban inaccessibility meant that a new strategy was needed by the ANC, particularly as opinion polls now suggested that battleground metros such as Johannesburg, Ekurhuleni, Tshwane and Nelson Mandela Bay were electorally vulnerable and on the proverbial knife edge (Madia 2019). A re-think and a robust electioneering campaign were needed to access the registered voter population within the entire metro urban space, and one way of tapping into this urban audience for both the ANC and the DA was through a multiplicity of communication avenues to guarantee on-target campaign message communication. Twitter was identified as an urban gateway to millions of metro voters in the 2016 LGE by each party's social media managers at the time, the DA's Aimee Franklin (2018) and ANC digital communications head Athi Geleba (2018), who confirmed that Twitter had become an important urban constituency communication tool.

In keeping with this battleground scenario that played out in several metropoles during the 2016 LGE, this paper attempts to answer whether the ANC and DA recognised the opportunity offered by Twitter; and how each party strategically and appropriately used the microblogging site as an urban electioneering weapon to optimise its impact.

To provide context, the paper begins by situating this study within John Petrocik's 1996 issue ownership theoretical framework and its relevance for South African elections. Following this, the researcher briefly examines how political communication has developed digitally with social networking sites such as Twitter. Acknowledgement is also made of how former United States (US) President Donald Trump and other global leaders have increasingly leveraged the microblogging platform for digital political communication purposes. The methodology section provides a truncated outline of the data collection and data analysis processes, followed by the main results and conclusion of the study. 


\section{THEORETICAL FRAMEWORK}

\section{Issue Ownership Theory}

Dhawraj (2019) asserts that studies spanning several decades illustrate how election campaigns are impacted by many factors such as party identification, ideological biases, appraisals, policy assessments, ethnic and race matters, gender persuasions, political candidate image constructions, and wider emotional appeals. Rooted in agenda-setting and priming theories, issue ownership theory has its genesis in salience theory, voter identification studies, voting analyses and political issues research (Cha, Suh \& Kim 2015, p. 309). For the purposes of this paper, John Petrocik's seminal 1996 theory on issue ownership is used to explain how political parties emphasise and downplay election messages. In his work, Petrocik (1996, p. 826) used the 1980 US presidential polls to show how political parties owned a set of electoral issues and were better at handling than a political opponent. Not only does this handling entrench dominance in voters' minds over time, issue handling is also about brand entrenchment. Issue ownership literature further reveals that apart from how political parties are judged on their handling of past election issues and the extent to which voters identified with that particular party, other elements which drive issue ownership include topics highlighted in manifestos, media priming, group identities, perception of political leaders and party identification (Dhawraj 2019).

The counter argument is that South African politics has not matured to a point where race and racial identity has decoupled from electoral choices. Scholars such as Everatt (2014), Ferree (2011, pp. 1-5) and Schulz-Herzenberg (2009, p. 32) maintain that South African vote choices boast an unmistakable racial imprint with party identification, party images, ethnicity and race being dominant and powerful predictors. Labelling the country's election cycles as a de facto racial census whereby black Africans vote for one set of political parties and white voters choose a different set of parties, Everatt (2014, pp. 12-16), for example, argues that South African elections are unique in this sense. Ferree $(2011$, p. 8) further describes South African elections as race-based with 'racial identities' acting as 'powerful, pervasive, divisive' heuristics embedded in decades of separate racebased policies under apartheid. Parties such as the ANC have subsequently been rewarded for abolishing that system, with voters supporting the governing party as an extension of their liberated identity. Within such a context, the electorate pays little or no attention to issues, policies or other politics-as-usual factors that define other established democracies. Feree (2011, pp. 59-61) further argues that because South African voting patterns are intricately tied to the so-called 
liberation dividend, it is difficult for opposition parties to make any inroads if there is little or no 'liberation' association. This rigidity and inflexibility in vote choice represents approximately $90 \%$ of South African voters.

\section{Social Media, Social Networking Sites and Twitter for Political Campaigning}

Following the end of the Second World War, political communication underwent four major realignment processes or four separate ages of development. While the press dominated the first age, limited television penetration defined the second age. It was only during the third age that multi-channel radio and television offerings took off. The fourth age of political communication is still in constant motion, mostly identifiable by its affinity for technology reshaping communication processes (Blumler 2013, p. 2015). Social media and social networking site usage for political campaigning is one manifestation of this still-developing fourth age and has consistently increased since former US President Barack Obama pioneered their use during his two-term presidencies. Twitter's infamy nowadays, however, is possibly because of the way in which Obama's successor Donald Trump used the microblogging site during his single-term presidency. Apart from Trump using Twitter to attack mainstream media, he also used the social networking site as his de facto megaphone (Stelter \& Disis 2016). Buncombe (2018), for example, argues that at the time of Trump's 2016 election social media functioned as the battleground and Twitter became his main communication weapon. Key to Trump's success in the 2016 US elections was in part due to how he used Twitter to disrupt the political sphere by cutting out the middlemen of politics, including big media corporations and reporters considered essential for campaigning, and setting his own editorial agenda instead. Landers (2017) even speculated that Trump's tweets enjoyed more currency than official White House statements, with whatever was tweeted from his personal account serving as official US presidential policy and government policy speak.

Globally, major politicians have become omnipresent on Twitter which is fast-emerging as the ideal political medium for the quick expression of political ideas. Ahmed (2018) labels this use of Twitter by diplomats, heads of state and leaders of intergovernmental bodies for outreach activities 'Twitter diplomacy'. Trump, again, is perhaps the best illustration of this. Whatever Trump said on Twitter became news. Trump himself confessed to the Financial Times that 'without the tweets, I wouldn't be here' - in reference to his winning of the 2016 elections (Trump 2019a; Trump 2019b). Research by Marsteller (2017) furthermore confirms that Twitter is now the social networking site of choice for $92 \%$ of all United Nations (UN) member states, with some 856 separate Twitter accounts and 356 million 
followers identified to represent governments. Barring Germany's Chancellor Angela Merkel, every European government has a presence on Twitter. Of the other continents, Nicaragua remains the only Latin American nation without a presence on Twitter. In Africa, Asia and the Pacific Rim string of nations, only 15 are not on the platform.

South Africa has the reputation of being the most active Twitter user on the African continent with more than eight million subscribers (Vermeulen 2018). Although social networking sites such as Facebook, Twitter, YouTube and Flickr were used to a limited degree in the 2009 general elections (Fakir, Bhengu \& Larsen 2010, pp. 112-117), the use of such platforms proved vital in the 2014 and 2016 elections. At the time of the 2014 general elections, there were approximately nine million Facebook and five million Twitter users. It was this high social networking site penetration coupled with accelerated smartphone adoption that made the 2014 elections perhaps the country's first digital elections (SABC 2014). For that poll, social networking sites promised an Obama-esque flavour to campaigning, with major parties such as the ANC seizing the opportunity to engage with supporters in a disintermediated way. Aside from tweeting, they also created conversations around their policies. At that time, the DA's Twitter handle boasted only 77300 followers compared to the ANC's 120000 followers (SABC 2014).

While television, radio, print and other forms of traditional media still occupied a dominant position within a tried-and-tested media campaign toolkit in the 2016 LGE, parties and political leaders could no longer afford to ignore the germination of political discourse that mediums such as Facebook and Twitter injected into overall campaigning. Twitter especially noted a significant spike in the ANC and DA's followers leading up to the 2016 LGE. The ANC's follower base, for example, grew 144\% from 120000 in 2014 to 293000 followers. The DA, too, grew its follower base from 77300 followers in 2014 to 209 000, an increase of $170 \%$. More importantly, the impact of Twitter on both parties' media mix was such that each increased their tweets by approximately $150 \%$ in the two years between 2014 and 2016. Table 1 below illustrates the increase in the tweets in each party, again illustrating the importance of Twitter as a digital political communication medium.

Table 1: Twitter presence in the ANC and DA 2011-2017

\begin{tabular}{|l|c|c|c|}
\hline \multicolumn{4}{|c|}{ African National Congress (ANC) } \\
\hline Year & Followers & Following & Tweets \\
\hline 2011 & Unknown & 6570 & 11100 \\
\hline 2014 & 120000 & & \\
\hline
\end{tabular}




\begin{tabular}{|l|r|c|c|}
\hline 2016 & 293000 & 8457 & 29100 \\
\hline $2017^{*}$ & 394000 & 8673 & 41600 \\
\hline \multicolumn{3}{|c|}{ Democratic Alliance (DA) } \\
\hline Year & Followers & Following & Tweets \\
\hline 2011 & 1500 & 26100 & 26900 \\
\hline 2014 & 77300 & 26800 & 64100 \\
\hline 2016 & 209000 & 26500 & 81500 \\
\hline$* 2017$ & 351000 & Unknown \\
\hline
\end{tabular}

* The researcher considered it necessary to depict changes in the ANC and DA's Twitter accounts exactly a year after the LGE on 3 August 2016. These numbers were extracted on 3 August 2017 to illustrate the growing popularity of Twitter.

Source: ANC 2019; Democratic Alliance 2019

\section{The Rise of the Digital Urban Electioneering Platform}

A wealth of literature across multiple disciplines indicates an intimate relationship between digital technologies and urban spaces (Dhawraj 2019). Brighenti (2010) labelled this 'mediatisation' or digital communication as being a manifest reality of the collision between urban space and technology. Drucker and Gumpert (2016, p. 1366), for example, provide evidence that 21st century cities brim with communication interactions of all sorts, shapes and sizes. Urban spaces are now branded as 'communicative cities' and 'environments of communication' and digital technologies thus give the urban space an added identity. Urban spaces are also known to be highly politicised; this is why political parties deliberately target these densely-populated areas (Bernstein 2019, p.19). Coupled with higher literacy levels and pronounced technology adoption (in terms of higher Internet connectivity and multiple device access), these factors make the urban political space ripe for the proverbial picking. One method of accessing these urban audiences is through social networking sites such as Facebook and Twitter, both of which Lim (2014) argues are 'mostly urban' interactive platforms. Smartphone access and affordability add to their widespread usage. Elections in India, Singapore and Malaysia are some examples where this has manifested (Lim, 2013, 2014; Mir, 2016; Nass, 2016).

Similarly, the South African urban space is highly connected with Internet access leveraged in many homes, at work and in study institutions or through the simple use of a personal hand-held mobile device. Statistics South Africa (Stats SA) show that a large proportion of so-called urban residents are connected to the WWW in some form or another. Numbers drawn from its 2016 General Household Survey estimates that $24 \%$ of households access the Internet at home, 
at an Internet café or educational institution. More remarkable is the revelation that mobile devices are increasingly being used to go online. Approximately $120 \%$ of urban residents access the WWW from multiple devices, pointing to the popularity of such digital technologies, again bolstering the idea that urban spaces are technology-filled. In addition, mobile handheld devices such as cellular phones and tablets are the choice of most urban dwellers with Internet connections. Although Internet access was fairly low in non-urban areas if and when logged on from home, work, an Internet café or a study institution, mobile devices were relatively popular (Statistics SA 2016, sec. 13 pp. 57-59). Numbers from the survey also confirm that urban residents are far more literate than their rural counterparts: $98.2 \%$ of all urban citizens aged 20 and above were functionally literate (Statistics South Africa 2016, sec 4: p. 20) (see Table 2 below).

Table 2: Percentage of South Africans accessing the Internet in 2016

\begin{tabular}{|l|c|c|}
\hline Internet Access & Urban & Rural \\
\hline Home & $23.5 \%$ & $2.0 \%$ \\
\hline Work & $39.2 \%$ & $3.9 \%$ \\
\hline Mobile device & $119.6 \%$ & $38.3 \%$ \\
\hline Net café / educational facility & $23.6 \%$ & $3.2 \%$ \\
\hline
\end{tabular}

Source: Stats SA 2016: sec 13, pp. 57-59

Additionally, municipal elections illustrate that these five-yearly polls offer an ideal time in which to establish conversations about urban spaces. These elections act as triggers for interrogative discourse about the urban arena, affording politicians and voters alike the opportunity to populate digital spaces with their concerns. Politicians thus realise the importance of the densified urban space, pointing to why political parties carefully consider election campaign strategies in urban centres. For them, population density translates into message concentration with concomitant minimal expending of scarce election resources. Growing evidence also exists that targeted political communication, especially in urban areas, yields improved results for political parties. In reporting back on a survey of India's 16th Lok Sabha 2014 elections Ahmed (2015) claims that the use of modern media techniques coupled with more creative urban electioneering increases votes for parties. This targeted political canvassing yields higher turnouts and inevitably raises levels of political consciousness. Trump, too, used skilful urban political communication through social networking sites in the 2016 polls to deliberately suppress turnout figures for the traditional urban voter base of his main rival, Hillary Clinton (Balz 2017). 


\section{METHOD}

\section{Grounded Theory as the Main Method}

Grounded theory was the main research method used for this study because it permits theory to emerge from the data, invariably leading to new ideas to build theory inductively. First conceptualised by sociologists Barney Glaser and Anselm Strauss in their 1967 study The Discovery of Grounded Theory, grounded theory argues in favour of a fresher method of understanding the social world and a context-specific method to challenge the domination of existing theories at the time. Hence, grounded theory does not test existing theory but rather involves the inductive process of data collection and data analysis to generate new theory, which is said to be 'grounded' in the examined data (Glaser 1978, p. 27). A typical grounded theory study involves multiple rounds of simultaneous data collection and data analysis through open coding, memo writing and theory creation through the emergence of categories within the data set. Through theoretical sampling, constant data comparisons of existing and newer data are used until theoretical saturation is achieved - or newer information around categories is exhausted. Once theoretical saturation is achieved core categories emerge from the data, informing an emergent substantive grounded theory. Grounded theory therefore comprises a few components, namely openness, immediate analysis, coding and constant comparisons, writing memos, theoretical sampling, and the writing of a substantive theory (Charmaz 2014, p. 55).

\section{Sampling and Units of Analysis}

Asiamah, Mensah and Oteng-Abayie (2017, pp. 1613-1616) confirm that predetermined population parameters refine the general population to a target and accessible population in qualitative research. For this paper, the ANC and DA's 2016 LGE tweets served as the accessible and target populations. Further sample refinement included narrowing the purposively-selected corpus of accessed tweets from only the @MyANC and @Our_DA handles between 1 May 2016 and 31 August 2016. Each tweet then served as a unit of analysis (or social artefact). Importantly, only written text within a tweet was analysed with no click-throughs to external shared links, videos or images. Following this, each party's 2016 LGE manifesto (social artefact) was then purposively and theoretically sampled, in accordance with grounded theory. While the publicly available manifestos served as the accessible and target populations, the only population parameter applicable was that they both had to be from South Africa's 2016 LGE. Each word, sentence, paragraph, table and graphic in this instance served as the unit of analysis. 


\section{Data Collection}

Data collection was guided by grounded theory data collection protocols, including theoretical sampling of the election manifestos. Both the ANC's and DA's 2016 LGE corpus of tweets were manually collected. Once the vast data sets of both these tweets were saved into public display format (PDF) files, they were stored onto a laptop, and migrated to the NVivo Pro 12 software program. The initial corpus of tweets comprised some 36 PDF files, with the ANC's total tweets amounting to 5400 and the DA's 7200 for the period between 1 May 2016 and 31 August 2016. During the initial open coding phase, data cleaning further reduced this sample. This cleaning of both the ANC's and DA's 2016 LGE corpus of tweets was minimal, and did not affect each party's final sample size to any large extent. The publicly-available LGE manifestos of both the ANC and DA were retrieved from each party's website in April 2016. Also, because this study relied mostly on empirical documentary evidence, ethical principles such as confidentiality and informed consent were needed and adhered to only with the two semi-structured interviews with each party's social media managers.

\section{ANALYSIS AND FINDINGS \\ Refinement using Open, Axial and Theoretical Coding}

According to Adu (2019), the objective of data analysis is to systematically reduce raw data into workable and meaningful data sets in order to find some form of pattern and trend. When using grounded theory, the main aim of the various iterative data analysis coding processes (open, axial and theoretical coding) is firstly to select, simplify, and provide more abstract meanings and then to transform the data. Similarly, both data sets (the corpus of ANC and DA 2016 LGE tweets and manifestos) underwent rigorous three-tiered coding using NVivo Pro 12 for better organisation. Open codes were narrowed down to focused codes through abstraction, and repeated distillation resulted in several theoretical codes for the ANC and DA.

\section{The Findings and What They Mean}

Ultimately, the main aim of this study was to gauge whether the microblogging site, Twitter, did indeed serve as an appropriate weapon for the ANC and DA in the fight to capture the urban vote in battleground metros such as Johannesburg, Tshwane, Ekurhuleni and Nelson Mandela Bay; and if this facilitated the strategic ownership and domination of political issues. Also, Twitter's relevance as a party digital issue ownership medium could be verified and measured against each 
party's election manifesto only once the grounded theory analysis was completed. Only then could there be a decision as to whether Twitter performed as predicted, that is as an urban electioneering platform for the ownership of certain election issues. Findings from the rigorous analyses firstly revealed that the ANC used Twitter mainly for publicity-related reasons. The DA, on the other hand, used the platform to promote its 2016 LGE issues, while simultaneously using it as an urban electioneering portal to target battleground metros the party felt it stood a chance of winning. Secondly, intense data analyses of each party's corpus of tweets revealed that while Twitter's explicit use for campaigning in the 2016 LGE provided issue ownership functionalities for each party, some owned issues were implicit. Thirdly, Twitter was confirmed to be a voter mobilisation tool, in agreement with other studies such as Chang (2014). However, for purposes of this paper, voter mobilisation occurred under two very different contexts, namely when political parties sought to spread publicity around their campaign trail (as proven with the ANC); and when political parties needed to activate potential voters around certain self-generated and media-primed owned party-political issues (as illustrated in the case of the DA).

On the first major finding, limited alignment was found when the ANC and DA's 2016 LGE corpus of tweets were compared against each party's election manifesto. Despite it being a local government election, each party's corpus of tweets mostly reflected national as compared to local issues. In the case of the ANC, issues such as 'delivering basic services', 'cleaning up local governance', 'ensuring accountability of elected municipal officials' and 'improving municipal capacity for better delivery' were the only manifesto issues picked up within the party's corpus of tweets. Other manifesto issues such as 'creating jobs at local government level', 'addressing crime', 'providing more educational and health facilities', 'introducing more mixed communities' and 'going greener in terms of cleaner communities' were virtually non-existent in the party's tweets. Like the ANC, the DA also promoted only some of its manifesto issues. Tweeted issues included 'creating jobs through more private sector investment', 'being more responsive to service delivery and basic services' and 'tackling local government corruption'. An implied inference, however, is that this phenomenon probably occurred because of Twitter's technological immediacy facilitating resonance with followers in real time. Predictively, the deduction then is that while a party's election manifesto is a rich source of party-political issues as proposed by Petrocik (1996), these were executed with limited success for both the ANC and DA in the 2016 LGE.

Consistent with Petrocik's (1996) issue ownership theory, however, the DA followed through with the media's framing of election issues. It chose to concentrate its energies on focused negative messaging against the ANC 
together with a simultaneous positive promotion of its core messages and battleground metro mayoral candidates. These party-political issues translated into owned issues for the DA. For example, one strain of focused negative issue messaging involved the ANC president, and on 30 June 2016 the DA reported on a R4-billion jet his party was purportedly buying. This received 644 retweets under the hashtag \#JobsNotJets, proving the DA's strategy was energised over Twitter. On the same day, the DA's Johannesburg mayoral candidate, Herman Mashaba, tweeted a similar message regarding Zuma's planned wastage of taxpayer monies. This focused message received a further 111 retweets, energising his party's negative campaign against the ANC and its campaign figurehead. Throughout the day, the DA tweeted more \#JobsNotJets tweets, attracting approximately 500 more retweets and by inference added opportunities for its focused electoral messaging to spread over Twitter. Similarly, the DA's focused messaging tweets around its battleground metro mayors like Herman Mashaba (Johannesburg), Solly Msimanga (Tshwane) and Athol Trollip (Nelson Mandela Bay) were able to energise the campaign. This was helped in part by the consistent tweeting and retweeting by other affiliated party-political Twitter accounts. The DA's promotion of its party-political issues in the 2016 LGE also extended to the way the party promoted a set of core issues it had strategised and devised around the elections. Franklin (2018), for example, confirmed that all campaigning in the 2016 LGE was centred around the DA's set of core issues, namely to 'stop corruption, create jobs and deliver better services'. Influencers were also used aggressively to drive these core issues in volume over Twitter, boosted in the main by catchy hashtags which were heavily promoted, such as '\#VoteForChange'.

Another arm of the DA's focused 2016 LGE campaign messaging was its communication around the Ipsos opinion polls which showed how close the race was between the ANC and DA in the battleground metros. Using these in its favour, the DA continued tweeting the outcomes of the Ipsos polls as part of its focused messaging drive to ensure optimal voter mobilisation. For example, on 21 July 2016 the party's tweet 'Latest \#IPSOS poll puts us ahead in NMB, JHB \& Tshwane, but it is neck-\&-neck. Many voters still undecided. Your vote can win it on Aug 3!' was retweeted 35 times and 'liked' 27 times, adding to the message's amplification. Earlier, successive tweets from the Ipsos polls had gained further traction with 93139 and 154 retweets. Other tweets such as 'Latest \#IPSOS puts us 9\% ahead of the ANC in Tshwane! We can win, but we need every supporter to vote on 03 August' drew hundreds more retweets, again ensuring the DA's focused messaging around the Ipsos polling in battleground metros received the necessary energy to possibly impact voters.

Message-sharing by other DA-affiliated accounts was also indicative of this particular voter mobilisation activation adopted by the DA. By repeatedly and 
consistently using focus tweeting on how close the race was in the battleground metros, the DA could have tipped the electoral scales in its favour by ensuring that voters were constantly appraised of how a single vote could mean either an ANC-led local government or one governed by the DA. Additionally, it was also earlier confirmed that interaction with party-political content over Twitter does find resonance in offline political expression (Chang 2014).

The other deduction is that the DA's consistent 'focused' negative messaging on the ANC, including discrediting its leaders such as Zuma and ANC metro mayoral candidates, could have succeeded in suppressing ANC voter turnout on election day. While the DA's broad aim was to repeatedly focus on ANC weaknesses, there was also a concerted effort by the DA to flood its own Twitter timeline with so much negativity around the ANC that even ANC partisans would become more disillusioned with their party and choose to stay away on election day. This pointed to the probability that the DA may have wanted to set the election agenda. ANC head of elections, Fikile Mbalula, confirmed this in 2018, attributing his party's poor showing in a few of the metros to the trend of ANC partisans boycotting the polls instead of voting for another party (Dlamini 2018). This deliberate suppression of the ANC's voter turnout in battleground metros meant that the DA's negative messaging had indeed affected the ANC's support base. This concurs with what Ahmed (2015) and Nass (2016) had found in their understanding of this development in the 2014 Indian general election and 2016 US presidential elections respectively.

Conversely, the ANC's lack of focused messaging on Twitter illustrates that a clear communication strategy is needed, particularly during a major election campaign. Also, there has to be buy-in from other affiliated party account holders such as prominent ANC politicians and party-political representatives, to ensure message concentration is achieved around the party's key electoral messages. This was not the case in the 2016 LGE. Instead, the ANC's electoral messaging lacked focus, diluting any kind of issue ownership over the micro-blogging portal. When its messages were retweeted, this was more to show some form of allegiance to the ANC brand that other supporters had missing by not being wherever ANC officials were campaigning. This electronic diary element for the ANC was fixed on spreading the word and was not anchored in any particular electoral issue messaging highlighted in either its manifesto or other communication. This communication and planning disjuncture does point to the ANC's sporadic and uncoordinated 2016 LGE Twitter campaign, a matter the party could attend to in future election campaigns. What did work for the ANC, though, is how the visual and real-time aspects of Twitter permitted the party to implicitly entrench its brand. Using the social networking site as a simple publicity tool, Twitter was leveraged to show its leaders dressed in bright ANC regalia interacting with 
ordinary supporters at places like taxi ranks, train stations, church gatherings and hawker stalls. This is in alignment with the party's core constituency, poorer working-class South Africans such as gardeners, domestic workers and street vendors. This type of grassroots interaction would not work with urban middleclass residents; the ANC itself lamented the fact that the urban middle class did not attend its rallies or similar party-political events (Sunday Independent 2013; Everatt 2014, p. 14). Therefore, the ANC used forums such as specially-convened meetings with professionals and similar stakeholders to communicate the party's 2016 LGE message across class.

This implicit manner of using Twitter to publicise its vast electioneering campaign helped the ANC overtly own the issue of being a caring, pro-poor, community-driven political party. Its leaders were often shown on Twitter visiting old age homes, crèches and other such interactions during the campaign trail. This sought to endear them to the ordinary citizen, portraying them as being more human and less aloof than an out-of-touch politician. The sheer scale of the ANC's publicity in the 2016 LGE campaign over Twitter also implicitly sought to convey the issue that there was a political party over 100 years old that was still relevant, professional, powerful and possessing the capacity to be in every part of the country. Through its well-publicised 2016 LGE Twitter electioneering campaign, the DA was also able to demonstrate to South African voters, the media and other political rivals that it was a serious political contender with the necessary electoral muscle to be every where. This implicit issue ownership also allowed the party to further cement its brand. Like the ANC leaders, DA leaders were shown kissing babies, interacting with poor communities on walkabouts and home visits, and hugging old pensioners to illustrate the issue, that is of it being an attentive, empathetic, caring political party.

To conclude, neither the ANC nor DA fully subscribed to issues highlighted in their election manifestos as there was no perfect alignment between promises made to voters and what each party tweeted in the 2016 LGE. While the ANC's random use of Twitter amounted to creating hype around its election campaigning activities (voter mobilisation), the DA used the micro-blogging site to react to the external environment and to set an altogether different party-political issue agenda from its manifesto issues. Notably, in identified battleground metros it observed that the media had primed these as possible areas which it could win from the ruling party. Using focused messaging through a steady stream of negative tweets, the DA chose to tailor-make its own party-political issue agenda in these battleground metros to activate potential voters to choose it over other political offerings (voter mobilisation). Positive issue messaging crafted around the leadership traits of these battleground mayoral candidates in Ekurhuleni, Johannesburg, Tshwane and Nelson Mandela Bay ensured the party stayed on- 
message, as envisaged in its broader communication objectives for this poll. This targeting of a few battleground metros and the intentional suppression of turnout by political rivals was repeated some months later in the 2016 US presidential elections, where President Trump deliberately identified 13 battleground states, while simultaneously strategising to keep Clinton's turnout in key states among key constituencies at a minimum. In addition, both the ANC and DA tapped into the implicit qualities of Twitter to show voters that both parties could be everywhere, with the sheer scale, volume and ability to be omnipresent on the rigorous four-month election drive. Besides communicating a message of being in touch and very human, like the poor voters they interacted with on dusty roads, dirty taxi ranks and crumbling mud houses, the issue both the ANC and DA aimed to own was that of a caring and empathetic party with which voters could identify.

In the final assessment, however, there is a need to ask critical questions of both ANC and DA usage of Twitter in the 2016 LGE:

- what they did right;

- what they did wrong;

- did they meet their communication targets;

- were there any misses;

- what could have triggered such digital political communication missteps over Twitter?

- was this because they responded wildly and in an uncoordinated way because of emergency issues?

In the case of the ANC, this study showed through deep analyses and written memos that the party did indeed use Twitter to publicise its 2016 LGE campaign. However, in doing so, the party missed several opportunities to effectively utilise hashtags for party-political issue mobilisation and use the medium for urban electioneering micro-targeting. Instead, the ANC's 2016 LGE campaign on Twitter came across as sporadic and uncoordinated - sometimes even disjointed. When it came to the DA, the party successfully used Twitter not only to publicise its nationwide 2016 LGE campaign, but also to advance certain issues it sought to promote over the platform. Hashtags were just one part of this party-political focus message mobilisation, especially in identified battleground metros where the party reasoned it could win votes from the ANC. Explicit negative messaging ensured that the party attacked their political opponent, to the point where it suppressed the ANC's turnout in this election.

Thus, the basic argument of this paper remains that microblogging site Twitter is an urban electioneering tool that allows political parties to own issues. 
The logical starting point for this proposition is for political parties and politicians alike not to focus exclusively on issues highlighted in their election manifestos but rather to claim issues as the election campaign develops. Central to this thesis is not to allow a party's issue agenda to be determined by reacting to everything in the electioneering build-up, but to gauge how reactions and strategies (both offensive and defensive) can be linked to a few issues which develop during the course of the campaign.

In the 2016 LGE, the ANC and DA were South Africa's biggest political players electorally, in terms of both resources and incumbency. With state resources at each party's disposal (the ANC is present in virtually every tier of government while the DA controls one province and several local municipalities), the implicit inference from their corpus of tweets reveals that they both sought to come across as well-resourced political players by being everywhere. They both sought to be portrayed as caring and pro-poor by using extensive door-todoor campaigns and walkabouts; and they both sought to promote their most prominent leaders positively to illustrate they too were as human as ordinary voters. These implicit issues sourced from the ANC and DA's corpus of tweets therefore served as alternative sources of issues to be owned during the 2016 LGE campaign trail. Findings from this study demonstrated alignment with Petrocik's (1996) issue ownership theory, in terms of issue-claiming through media framing, constituency-based associative issue ownership, issues highlighted in election manifestos and the images of leaders serving as issue-driving heuristics. However, Twitter's use by the ANC and DA in their 2016 LGE campaigns also endeavoured to implicitly convey party-political digital issue ownership over the medium.

\section{Theoretical and Practical Contributions of this Study}

The primary theoretical contribution of this paper is towards the discipline of communication science. However, it includes the integration of a microblogging site such as Twitter into the digital political communication media mix for political parties, for the promotion of party-political digital issue ownership, especially around heightened electioneering cycles. As election campaigns increasingly migrate to the technological space, there will be added pressure on politicians and political parties to determine how best to optimise that space. Empirical data from this study illustrates that when clear communication strategies are in place - coupled with the help of influencers - consistent messaging can drive home a particular electoral message. In the case of the DA, although this was part of the party's anti-ANC negative advertising campaign, the use of uniform hashtags, repeated messaging, negative infographics and the fact that South Africans were accessing this information on their smartphones while standing in line to vote 
at polling stations, ensured the party stayed on-message for possible electoral success. It was also highly likely that voters made emotional vote choices after viewing the DA's negative party-political messaging on their mobile phones (political persuasion).

One of the significant theoretical contributions of this study remains the fact that Twitter can be leveraged as an urban electioneering platform to micro-target potential voters. Empirical data from the DA's 2016 LGE campaign showed how the party used Twitter to audience-segment the urban voter by having a clear urban political communication strategy in place. Franklin (2018) provided evidence of this during her semi-structured interview: that the socalled battleground metropolitan municipalities of Nelson Mandela Bay and Johannesburg, Ekurhuleni and Tshwane were in the party's sights. This followed a number of internal and external surveys showing it stood a good chance of emerging as the dominant party in those areas. Together with a pronounced focus on party-political digital issue ownership by focusing on its anti-ANC messages (negative advertising), this communication arsenal was effected more within the identified metros. The mobile phone was the DA's instrument of choice for this urban audience segmentation.

In their semi-structured interview the ANC also acknowledged that their use of Twitter in the 2016 LGE was motivated by the urban factor, an opportunity to appeal to the urban voter present on the microblogging site (Geleba 2018). Add to this the issue of rapid urbanisation; and the fact that urbanised voters seek more accountability from government leaders indicated a substantial pool of persuadable voters which could be accessed and possibly convinced to vote for it. This is exactly what the DA did in the 2016 LGE. It used the factors of a fast-urbanising society coupled with a younger demographic being able to vote in 2016 to possibly win it more electoral support in urban areas. Together with the rest of the African continent, South Africa is also rapidly urbanising, with almost $64 \%$ of the nation's population now living in the eight metropolitan areas. This figure is poised to increase to $71.3 \%$ by 2030 and as much as $80 \%$ by 2050 (Bernstein 2019, p. 19). Urbanisation brings with it an expanded and educated middle class - a key constituency boasting access to technology, a class which is technologically-literate, owns multiple Internet-enabled devices to access information and recognises that the urban space is a highly fluid and politicised one. As in Malaysia, Singapore and more recently in the 2016 US presidential elections, the DA capitalised on Twitter's urban appeal, confidently using it as a digital urban electioneering platform to communicate its 2016 LGE political ideas.

Other notable theoretical contributions to this paper include Twitter's relevance to communication sub-disciplines such as political advertising, political marketing, political public relations, brand management and image 
management. The assumption that Twitter can aid or even further these elements of digital political communication transaction was supported by rich empirical data involving both the ANC and DA. In the case of the ANC, although it had not leveraged Twitter as an urban electioneering platform, it ensured that Twitter communicated its brand to all corners of the South African electoral landscape. Other traditional and non-traditional media could not have been so successful, because of either human capital or financial considerations. The ANC needed only its members and prominent leaders to be dressed in party colours (green, black and gold) for the party's brand to enjoy traction in terms of recognition. When it came to the DA, Twitter ensured that party representatives such as the metro mayoral candidates were easily identified, including their capabilities once elected to office, via information graphics and consistent tweeting. These factors ensured that Twitter was optimally used by the DA for its political advertising, political marketing, political public relations, brand management and image management efforts.

\section{CONCLUSION}

Results emanating from this three-phased grounded theory study point to new knowledge by exploring how Twitter was activated as a digital urban electioneering and digital party-political issue ownership platform, notably for the DA. The party also used the portal to mount an aggressively negative political campaign against the ANC, pointing to issue ownership of a different texture. This study also established that both the ANC and DA used Twitter as a digital political communication avenue; and in the case of the ANC, it was shown that the party also used Twitter as an electronic diary.

This study is, therefore, significant because it contributes to an expansion of the way social networking sites impact the digital political communication and digital political persuasion process. In the case of the DA, Twitter was shown to be a digital political mobilisation tool, especially in how the party used negative advertisements and smartphone technology access for consistent voter appeals.

As with any ambitious study, there are a few limitations. Researchers can use larger sample sizes, more social networking platforms (such as YouTube, Facebook and Instagram) and more election cycles for a longitudinal study. Recognising that there currently exists a dire shortage of studies on social networking in African elections, a novel idea would be to conduct a multi-country African study to comprehend the way continental democracies embrace electronic-related campaigning and digital political communication. The research done here could also be replicated and applied to other African nations as well as other developing countries outside this continent to deepen an understanding of how political 
communication is fast altering with technological leaps. Thus, more scholarly work in political communication and the use of social media in political communication is urgently needed.

\section{Acknowledgement}

This article is based on the author's PhD thesis entitled 'A conceptual framework for digital political communication to promote party-political issue ownership via an urban electioneering platform', University of South Africa, Pretoria, 2019.

\section{REFERENCES}

Adu, P 2019, A step-by-step guide to qualitative data coding, Routledge, Oxford.

African National Congress 2016, Local Government Elections Manifesto. Available online: https://www.anc1912.org.za/

African National Congress 2016, 'My ANC 2016 local government elections feed', https://twitter.com/MYANC [1 May 2016]

African National Congress 2019, 'My ANC GROW South Africa', https://twitter.com/MYANC [25 March 2019]

Ahmed, S \& Kokil, J 2015, 'The 2014 Indian general election on Twitter: an analysis of changing political traditions', Proceedings of the Seventh International Conference on Information and Communication Technologies and Development (ICTD '15). Association for Computing Machinery, New York, Article 43, pp.1-5. DOI:https://doi.org/10.1145/2737856.2737889

Ahmed, W 2018, Amplified messages: how hashtag activism and Twitter diplomacy converged at \#ThisIsACoup - and won.

http://blogs.lse.ac.uk/impactofsocialsciences/2016/01/07/how-hashtagactivism-and-twitter-diplomacyconverged-at-thisisacoup/[15 April 2018]

Asiamah, N, Mensah, HK \& Oteng-Abayie, E 2017, 'General, target, and accessible population: demystifying the concepts for effective sampling', The Qualitative Report, vol. 22 no. 6, pp. 1607-1621.

Balz, D 2017, Rural America lifted Trump to the presidency: support is strong, but not monolithic. https://www.washingtonpost.com/politics/rural-america-liftedtrump-to-the-presidency-support-isstrong-but-not-monolithic/2017/06/16/ df4f9156-4ac9-11e7-9669-250d0b15f83b_story.html?utm_term=.0175ac1321dc. [12 December 2017]

Berkowitz, P 2016, City of Cape Town post-elections analysis. https://www.eisa.org.za/ eu/eu2016capetown.htm. [5 April 2017].

Bernstein, A 2019, 'We need to build cities of hope, not more houses in the veld', Sunday Times, 14 April, p. 19. 
Blumler, JG 2013, The fourth age of political communication.

http://www.fgpk.de/en/2013/gastbeitrag-von-jay-g-blumler-the-fourth-ageof-political-communication-2/ [25 August 2016]

Buncombe, A 2018, Donald Trump one year on: how the Twitter president changed social media and the country's top office. https://www.independent.co.uk/news/ world/americas/us-politics/the-twitter-president-how-potuschanged-socialmedia-and-the-presidency-a8164161.html [3 April 2019]

Cha, H, Suh, JW \& Kim, JR 2015, 'The effect of issue obtrusiveness, issue congruence, and response strategies on the acceptance of crisis communication messages', Asian Journal of Communication, vol. 25, no. 3, pp. 307-326.

Chang, D 2014, 'Leveling the playing field: social media and politics in South Korea', Global Asia, vol. 9, no. 2, pp. 30-35.

Charmaz, K 2014, Constructing grounded theory: a practical guide through qualitative analysis, Sage, London.

Democratic Alliance 2016, Local Government Elections manifesto: Change that Moves South Africa Forward Again. https://www.da.org.za/campaigns/localgovernment-elections-manifesto-2016

Democratic Alliance 2019, @Our_DAhttps://twitter.com/Our_DA [25 March 2019/03/25]

Dhawraj, R 2019, A conceptual framework for digital political communication to promote party-political issue ownership via an urban electioneering platform, $\mathrm{PhD}$ thesis, University of South Africa.

Dlamini, P 2018, 'Fikile Mbalula wants new vote for troubled DA Nelson Mandela Bay metro', Businesslive, 29 March.

https://www.businesslive.co.za/bd/politics/2018-03-29-fikile-mbalula-wantsnew-vote-for-troubled-danelson-mandela-bay-metro/ [20 April 2018]

Drucker, S \& Gumpert, G 2016, 'The communicative city redux', International Journal of Communication, vol. 10, pp. 1366-1387.

Everatt, D 2014, 'Gauteng and the arrival of uncertainty', The Journal of the Helen Suzman Foundation, vol. 74, pp. 10-18.

Everatt, D 2017, 'New survey data shows Zuma cost the ANC dearly in the 2016 election', SABC, 6 April. http://www.sabc.co.za/news/a/2f5b4c8040b0627f 8977f9d9ce9b621f/New-survey-data-shows-Zumacost-the-ANC-dearly-inthe-2016-election-20170704 [10 April 2017]

Fakir, E, Bhengu, Z \& Larsen, JK 2010, 'Future imperfect: the youth and participation in the 2009 South African elections' Journal of African Elections, vol. 9, no. 2. pp. 100-117.

Ferree, K E 2011, Framing the race in South Africa, Cambridge University Press, New York.

Franklin, A 2018, Personal interview, 7 September. 
Geleba, A 2018, Personal interview, 8 October. Glaser, B \& Strauss, A 1967, The discovery of grounded theory: strategies for qualitative research, Sociology Press, Mill Valley, CA.

Glaser, B 1978, 'Theoretical sensitivity advances in the methodology of grounded theory', Sociology Press, Mill Valley, CA.

Ipsos 2016a, 'Polls: ANC and DA neck-and-neck in Joburg', Press release, 4 April. Ipsos 2016b, 'Polls: ANC slightly ahead in Tshwane', Press release, 11 April.

Ipsos 2016c, 'Polls: DA maintains strong lead in Nelson Mandela Bay', Press release, 18 April.

Landers, E 2017, 'White House: Trump's tweets are 'official statements', CNN, 6 June. http://edition.cnn.com/2017/06/06/politics/trump-tweets-official-statements/ index.html [8 January 2018]

Lim, M 2013, 'Many clicks but little sticks: social media activism in Indonesia', Journal of Contemporary Asia, vol. 43, no. 4, pp. 636-657.

Lim, M 2014, 'Seeing spatially: people, networks and movements in digital and urban spaces', International Development Planning Review, vol. 36, no. 1, pp. 51-72.

Madia, T 2019, 'Unlocking the middle class: the ANC's suburban access conundrum', News 24, 6 April.

Mantashe, G 2017, Discussion document on ANC organisational report.

http://www.anc.org.za/sites/default/files/National\%20Policy $\% 20$ Conference\%202017\%20Organisation al\%20Renewal.pdf [15 May 2017]

Marsteller, B 2017, Twitter is the prime social media network for world leaders, PRNewswire, 31 May. March 2018]

https://www.prnewswire.com/news-releases/twitter-is-the-prime-socialmedia-network-for-worldleaders-300466300.html [2

Mir, N 2016, 'Trump, Twitter and transformed political communication', Influence, 11 March.

http://influence.cipr.co.uk/2016/11/03/trump-twitter-transformed-politicalcommunication [15 December 2017]

Nass, J 2016, 'How Trump changed political communication forever', The Hill, 29 December.

Petrocik, JR 1996, 'Issue ownership in presidential election with a 1980 case study', American Journal of Political Science, vol. 40, pp. 825-850.

Schulz-Herzenberg, C2009, 'Elections and accountability in South Africa', ISS Paper 188, pp. 1-26.

South African Broadcasting Corporation 2014, 'Social Media fires up election season', @SABCOnline 24 March. https://www.sabcnews.com/sabcnews/ social-media-fires-up-election-season/ [1 May 2016]

Statistics South Africa 2016, General household survey 2016. https://www.statssa. gov.za/publications/P0318/P03182016.pdf [7 April 2017] 
Stelter, B \& Disis, J 2016, 'President-elect Trump's Sunday morning tweetstorm at the New York Times', CNN 13 November. http://money.cnn. com/2016/11/13/media/donald-trump-new-york-times/index.html [14 November 2016]

Sunday Independent 2013, 'ANC eyes middle class, urban voters', 16 June. http://www.iol.co.za/news/politics/anc-eyes-middle-class-urbanvoters-1533112 [3 April 2015]

Trump, D 2019a, After 52 years it is time for the United States to fully recognize Israel's Sovereignty over the Golan Heights, which is of critical strategic and security importance to the State of Israel and Regional Stability! https://twitter.com/ realDonaldTrump/status/1108772952814899200?s=03 [21 March 2019]

Trump, D 2019b, Today, it was my great honor to welcome Prime Minister @Netanyahu of Israel back to the @WhiteHouse where I signed a Presidential Proclamation recognizing Israel's sovereignty over the Golan Heights. Read more: https:// www.whitehouse.gov/presidential-actions/proclamationrecognizinggolan-heights-part-state-israel/ https://witter.com/realDonaldTrump/ status/1110242521400123394 [26 March 2019].

Vermeulen, J 2018, Twitter showing strong growth in South Africa, MyBroadband, 22 June. https://mybroadband.co.za/news/it-services/264929-twittershowing-strong-growth-in-south-africa.html [1 March 2019] 